\title{
Comunicação \& Educação: um olhar para a diversidade
}

Solange Martins Couceiro de Lima

Professora doutora do Departamento de Comunicações e Artes da ECA-USP.

E-mail:somartins@uol.com.br

Há mais de dez anos, a revista Comunicação \& Educação dedica-se a publicar as mais diversas reflexões sobre a interseção entre esses dois campos. Os artigos e diferentes seções defendem posturas, formulação de leis e diretrizes que, na educação formal, dêem atenção à Comunicação e orientem educadores a exercer e praticar, com seus alunos, a leitura crítica dos meios de comunicação. A outra face dessa defesa está no uso competente desses meios em sala de aula.

Ao perseguir fielmente esse interesse, o curso Gestão da Comunicação Lato Sensu - que é ministrado na ECA-USP desde 1993 e do qual esta revista faz parte - dedica uma das suas três especializações à gestão nos espaços educativos, com o intuito de formar profissionais atuantes na mediação entre o sistema educacional e a comunicação, para que ambas, Educação e Comunicação, sejam exercidas de modo democrático e dialógico.

Anteriormente a essas atividades, em 1986, o Núcleo de Comunicação e Educação - NCE foi criado na USP por um grupo de professores interessados nessa inter-relação. A eles acrescentam-se pesquisadores de diferentes níveis, graduandos, pós-graduandos, que formam um espaço não só de pesquisa científica, mas também de pesquisa-ação, formulando e implantando projetos para a sociedade ${ }^{1}$.

Em 1996, a Lei de Diretrizes Orçamentárias - LDO introduziu a idéia de que a educação não se limita à escola e aos meios formais/intencionais com os quais trabalha, mas é um campo amplo e encontra-se em processo na família, nas relações sociais, no trabalho, na sociedade, na cultura e nos meios de comunicação inseridos nesses ambientes.

Complementando a LDO, são instituídos os Parâmetros Curriculares Nacionais - PCNs para o ensino em todos os graus, os quais perseguem o ideal de uma educação para a cidadania, obtido não apenas por meio de uma educação mais abrangente em termos de vagas, mas também de um ensino de qualidade e docentes preparados e conhecedores dos avanços das pesquisas em diferentes áreas do conhecimento. Os PCNs, além de formularem diretrizes para as disciplinas curriculares, também incorporaram questões temáticas da sociedade brasileira que devem ser levadas para a sala de aula. São os chamados Temas

1. SOARES, Ismar de O. NCE: a trajetória de um núcleo de pesquisa da USP. Comunicação \& Educação, São Paulo: CCA/ECA/USP-Paulinas, ano $X$, n. 1, p. 111-113, jan./abr. 2005. 
comunicação \& educação • Ano XII • Número 1 • jan/abr 2007

Transversais, os quais englobam Ética, Saúde, Meio Ambiente, Orientação Sexual, Pluralidade Cultural, Trabalho e Consumo. Por serem considerados temas que envolvem problemáticas sociais atuais e urgentes, de abrangência nacional e mundial, fazem parte do cotidiano dos educandos e devem ser contemplados na perspectiva da interdisciplinaridade.

Quero ater-me ao tema Pluralidade Cultural, por considerar a diversidade étnica e cultural da sociedade brasileira, muitas vezes, alvo de preconceito e discriminação. Ao abordar esse tema, os PCNs propõem que a escola ensine que o espaço público democrático deve garantir a igualdade e a diversidade como direito, cooperar para a formação de uma cultura da paz baseada em tolerância, respeito aos direitos humanos universais e cidadania compartilhada por todos os brasileiros. Deve ainda promover a superação da discriminação e da exclusão, valorizando todos os indivíduos que formam a sociedade brasileira e o convívio entre eles, e, ao mesmo tempo, repudiar qualquer discriminação de raça/etnia, classe, religião ou sexo. Reconhece-se nessas orientações a crença numa educação cidadã, crítica, formadora de seres humanos conscientes de sua importância na sociedade em que vivem. Por outro lado, exigem do educador atitude correspondente com essas intenções, que implica a aprendizagem também por parte deles, no sentido dialógico, e a necessidade de revisão dos próprios valores, visão de mundo, conceitos e preconceitos, os quais também precisam ser admitidos e exorcizados.

Sabemos viver numa sociedade a qual nega seus preconceitos. Florestan Fernandes dizia que no Brasil temos preconceito de ter preconceito. O medo de ser considerado preconceituoso é mais forte do que o próprio preconceito. Sempre conhecemos alguém que consideramos preconceituoso: nosso vizinho, um parente distante, até um amigo, mas nós, não! O professor/educador deve ter conhecimento e consciência desse chamado racismo cordial (sic), se pretende ser um agente modificador de tal situação. Leis bem-intencionadas, ainda que fundamentadas, talvez se percam numa prática na qual o agente de sua implementação, no caso o educador, não esteja capacitado para a tarefa de colocá-las em prática.

Há tempos, pesquisadores brasileiros, brancos e afro-descendentes, que investigam temas ligados à questão racial na nossa sociedade, e integrantes do Movimento Negro reivindicam atenção para a necessidade de legislações envolvendo uma educação voltada para a desconstrução do racismo.

Nos anos 1980, as pesquisas centravam-se, prioritariamente, nas análises críticas dos livros didáticos e paradidáticos, apontando para as inúmeras representações estereotipadas e preconceituosas contidas nos textos e nas ilustrações com relação aos afro-descendentes, indígenas, mulheres, deficientes, trabalhadores e outras categorias sociais discriminadas. Outras preocupações aparecem nos debates e trabalhos acadêmicos sobre a socialização da criança negra e o papel da escola nesse processo. A proposta de se pensar currículos que atendam à diversidade étnica também surge nessas reflexões. A Fundação Carlos Chagas, instituição com importante papel na discussão desses temas, organizou em 1986 o seminário $O$ Negro e a Educação, publicado no ano seguinte ${ }^{2}$. 
Nos anos 1990, como resultado dessa luta antiga, o MEC e o Programa Nacional do Livro Didático instituíram um sistema de avaliação dos livros comprados pelo governo para serem distribuídos na rede de ensino pública. Com isso, mesmo as editoras iniciaram um trabalho que, se ainda não é o ideal, deu passos importantes no sentido de autores e ilustradores incluírem a diversidade em seus livros e cuidarem para não reproduzir estereótipos.

Com a LDO de 1996, os PCNs e as Diretrizes Curriculares Nacionais para todos os níveis de ensino, abre-se caminho para o atendimento específico dos afro-descendentes com a aprovação e a promulgação - em 2003 e 2004, respectivamente - da Lei 10.639, que institui as Diretrizes Curriculares Nacionais para Educação das Relações Étnico-Raciais e para o Ensino de História e Cultura Afro-Brasileira e Africana. O relatório elaborado pela Comissão do MEC, que, aprovado, deu origem à Lei, é peça muito interessante de diagnóstico da situação racial brasileira e contém proposta não só educacional, mas de abertura de diálogo com movimentos sociais para estabelecimento de princípios e compromissos de combate ao racismo, os quais, sem dúvida, precisam ser estendidos a todos os segmentos da sociedade e aos meios de comunicação.

Entretanto, mais uma vez voltamos a levantar a questão da necessidade do preparo de professores, educadores e dirigentes de escola para o cumprimento dessa tarefa. Uma das ações que, vinculando a comunicação e a educação, buscaram atender às novas orientações surgidas a partir dessas novas leis, diretrizes e parâmetros foi protagonizada pelo NCE, em parceria com a Prefeitura de São Paulo, de 2001 a 2005. Disso resultou a implantação de ações muito frutíferas no campo da educação/comunicação que podem ser conhecidas no artigo de Soares $^{3}$, citado anteriormente.

Como parte desse projeto para atender ao tema Pluralidade Cultural, um grupo de pesquisadores pós-graduandos e professores ligados ao NCE levou a escolas e delegacias de ensino de São Paulo um trabalho de capacitação que envolveu um número grande de educadores. Usando como recursos didáticos peças produzidas pela mídia, como propagandas, telenovelas e filmes, as palestras e debates visavam levantar questões relacionadas à diversidade étnica, ao racismo e aos estereótipos; pretendiam suscitar uma leitura crítica dos produtos midiáticos e mostrar como é importante levar esse exercício para a sala de aula. Os debates propunham também, entre outros objetivos, que os professores passassem a pensar o seu cotidiano em sala de aula e de que modo poderiam lidar com a diversidade e a convivência inter-racial no espaço escolar ${ }^{4}$.

Esses pesquisadores formam, atualmente, o Grupo Mídia e Etnia - GME e continuam atuando na extensão do conhecimento e na formação de educadores para atender à Lei 10.639 e ao tema do pluralismo cultural, ministrando palestras, oficinas, cursos e seminários; promovem, assim, a valorização do afro-descendente e o combate ao racismo. Ao trabalhar com metodologia que utiliza recursos imagéticos, a proposta deles é despertar a observação, a análise
3. SOARES, op. cit.

4. Informações obtidas com a doutoranda Luciene Cecília Barbosa, participante do projeto. 
e a crítica das mídias eletrônica e impressa, do cinema e da literatura. Sem abrir mão dos conteúdos curriculares, esse trabalho procura demonstrar a possibilidade de disciplinas como História, Língua Portuguesa, Artes e Geografia contribuírem na tarefa de prevenção do racismo, do reforço da auto-estima de alunos afro-descendentes e de uma visão crítica de nossa realidade social, formando cidadãos solidários ${ }^{5}$.

Os PCNs e as Diretrizes Curriculares são dirigidos a alunos de ensino fundamental e médio.

Gostaria de finalizar a apresentação deste volume da revista Comunicação \& Educação pensando na importância e na responsabilidade do ensino infantil e fundamental à formação do indivíduo. Na Semana da Consciência Negra de novembro de 2006, no jornal Folha de S. Paulo, dentre as várias matérias que a imprensa costuma publicar nessa semana - e infelizmente só nessa semana -, o caderno Folhinha, direcionado à criança, trouxe na sua edição do dia 18 depoimentos de crianças negras com idade entre 7 e 11 anos, vítimas de preconceito e discriminações de colegas de escola; são dolorosos, tristes. A identidade do indivíduo, processo dinâmico que se constrói ao longo da vida, tem na infância seu momento crucial. Valorizar a si mesmo, gostar de suas características físicas, é um aprendizado; o cultivo da auto-estima a que todos têm direito precisa ser baseado no respeito às diferenças, pois quem não é respeitado não aprende a se respeitar. Este deve ser um compromisso da sociedade brasileira, de todos os brasileiros, pois o problema do racismo não é um problema do negro, mas sim de toda a sociedade.

Embora esta revista tenha dedicado muito espaço às questões educacionais, foram poucos os artigos relacionando o racismo à educação. Espero que mais contribuições sobre o tema apareçam para debate. Afinal, se racismo se aprendeu na escola, está mais do que na hora de se aprender anti-racismo nela também.

\section{ARTIGOS NACIONAIS}

Este número da revista selecionou cinco artigos nacionais com temáticas bastante diversificadas, oferecendo várias possibilidades de leitura e discussão.

Em As histórias em quadrinhos para a formação de leitores ecléticos: algumas reflexões com base em depoimentos universitários, de Valéria Aparecida Bari e Waldomiro Vergueiro, discute-se a relação entre a leitura de HQ e o gosto pela leitura.

José Marques de Melo, em A utopia brasileira da mídia cidadã, conceitua como esta mídia é capaz de estabelecer convergências entre os sistemas midiáticos massivo e popular.

A mediação tecnológica nos espaços educativos: uma perspectiva educomunicativa,

5. MÍDIA E ETNIA, São Paulo: Prefeitura da $\mathrm{Ci}$ dade de São Paulo-Cone, ano 1, n. 1, 2006. de Ismar de Oliveira Soares, discorre sobre os desafios que os sites de relacionamento na internet representam para a educação.

A diversidade dos modos de ler e uma visão para além do ambiente físico é o que aponta Angela Maria Barreto, em seu artigo Os espaços de leitura. 
Maria Lourdes Motter e Daniela Jakubaszko, em Telenovela e realidade social: algumas possibilidades dialógicas, propõem categorias de avaliação que tornem possível verificar a interação entre o universo da telenovela e nosso cotidiano.

\section{ARTIGO INTERNACIONAL}

Em Comunicação e memória em tempos de repressão: uma análise interdisciplinar de "Memórias do cárcere" $e$ "Primavera con una esquina rota", Adriana Coelho Florent, da Universidade de Paris 8, fala sobre a questão da memória em vivências de prisioneiros políticos em tempos de repressão, analisando as obras de Graciliano Ramos e Mario Benedetti, respectivamente.

\section{GESTÃO DA COMUNICAÇÃO}

Maria Cristina Castilho Costa, em Contribuição dos cursos de especialização lato sensu para o desenvolvimento do campo da comunicação, relata a abordagem de uma das mesas temáticas do XXIX Intercom, mostrando que esses cursos cumprem importante função no desenvolvimento da ciência, no atendimento da sociedade e na profissionalização dos alunos.

\section{ENTREVISTA}

A entrevistada deste número é Maria Luiza Marcílio, professora do Departamento de História da USP. Ela conversa com Maria Cristina Castilho Costa e Consuelo Ivo, e defende a Declaração Universal dos Direitos Humanos como sendo o mais importante documento elaborado pelo homem.

\section{CRÍTICA}

Em $O$ discurso hegemônico de Veja $e$ a construção da imagem do pobre, Maria Aparecida Baccega e Aline Fernandes de Azevedo fazem uma análise crítica daquela publicação, apontando os sentidos hegemônicos em suas páginas, as estratégias de construção dos discursos e a produção de efeitos direcionais da leitura.

\section{DEPOIMENTO}

O premiado cenógrafo Cyro Del Nero relata, em Tornei-me o homo faber por excelência, os seus mais de 56 anos dedicados às artes cênicas, ao cinema, à televisão e aos meios de comunicação e entretenimento, além de projetos especiais, como o Pavilhão Brasileiro na EXPO 70, no Japão. 


\section{EXPERIÊNCIA}

No texto de Maria Elizabete Souza Couto, A televisão e o vídeo em sala de aula: uma experiência realizada com professores e alunos de história, são analisadas as mudanças ocorridas com a implantação de novas tecnologias de informação e comunicação, notadamente a utilização de programas de televisão e de filmes como elementos didáticos.

\section{POESIA}

Adílson Citelli traz para esta edição um escrito/poema do teólogo luterano Martin Niemöller, que possui forte ligação com poemas de Maiakóvsky e Brecht. Observa tais recorrências à luz do conceito de apropriação intertextual, sem, contudo, deixar de lembrar que as obras conservam diferentes identidades, originalidades e estilos.

\section{SERVIÇOS}

Criada em 1998, a REDARTE-SP é uma malha institucional que inclui bibliotecas, setores de museus, centros de documentação, de referência e de pesquisa, arquivos e outras organizações, públicas ou privadas, responsáveis por projetos ou espaços virtuais de informação em arte. Em REDARTE-SP: integrando recursos de informação em arte da cidade de São Paulo, Maria Christina Barbosa de Almeida e Paulo Simões de Almeida Pina propõem uma articulação capaz de desenvolver projetos conjuntos, uma organização de informação mais eficiente e maior acessibilidade aos equipamentos e espaços disponíveis.

\section{VIDEOGRAFIA}

Maria Ignês Carlos Magno utiliza dois filmes de naturezas diversas, mas que mostram personagens infantis que vivem duras realidades. Para isso, lança mão de Camelos também choram, uma narrativa sobre a vida de nômades no deserto de Gobi, e Crianças invisíveis, com sete curtas de vários países. Em ambos, há dois aspectos a serem considerados como temas básicos: a exclusão e a reflexão sobre a idéia do invisível.

\section{BOLETIM BIBLIOGRÁFICO}

As subseções Bibliografia sobre telenovela e Bibliografia sobre comunicação trazem livros, teses e dissertações relacionados às respectivas temáticas. Endereços úteis na internet pode contribuir para incrementar as tarefas cotidianas dos professores. 


\section{ATIVIDADES EM SALA DE AULA}

As três atividades sugeridas nesta edição por Ruth Ribas Itacarambi têm como temas a questão dos direitos humanos, o papel da educomunicação como alternativa para a construção da democracia e as mídias na sala de aula.

Resumo: A autora lembra que, dentre os Temas Transversais, a Pluralidade Cultural considera ser a diversidade étnica e cultural da sociedade brasileira, muitas vezes, alvo de preconceito e discriminação. Discorre sobre como a LDO de 1996, os PCNs e as Diretrizes Curriculares Nacionais abriram caminho para o atendimento específico dos afro-descendentes com a aprovação da Lei 10.639, que institui as Diretrizes Curriculares Nacionais para Educação das Relações Étnico-Raciais e para o Ensino de História e Cultura Afro-Brasileira e Africana. Levanta a questão da necessidade do preparo de professores, educadores e dirigentes de escola para o cumprimento dessa tarefa; cita uma das ações que vinculam a comunicação e a educação, protagonizada pelo NCE e seus pesquisadores, a qual levou escolas e delegacias de ensino de São Paulo a um trabalho de capacitação que envolveu grande número de educadores.

Palavras-chave: LDO, NCE, pluralidade cultural, afro-descendentes, História e Cultura Afro-Brasileira.
Abstract: The author reminds that, among Transversal Themes, Cultural Plurality is the one that points to the Brazilian society ethnic and cultural diversity, which is, many times, object of prejudice and discrimination. She reasons on how the Budget Guidelines Law, of 1996, the National Curricular Parameters and the National Curricular Guidelines opened space to specific attendance for afro-descendants with the approval of Law n. 10.639, that establishes the National Curricular Guidelines for the Education of Ethnic/Racial Relationships and to the Teaching of Afro-Brazilian and African History and Culture. She discusses the need of preparing teachers, educators and school managers to fulfill this assignment. She refers to an action of the Research Center for Education and Communication (NCE) that took to Sao Paulo public schools and state educational offices a qualification work that involved a big number of educators.

Keywords: Budget Guidelines Law; Research Center for Education and Communication; cultural plurality; afro-descendants; AfroBrazilian History and Culture 